\title{
Spark Plasma Sintering of a Hard Metal Powder Obtained from Hard Metal Scrap
}

\author{
Angélica da Cunha dos Santos ${ }^{a}$, Ana Lúcia Diegues Skury ${ }^{b}$, Angelus Giuseppe Pereira da Silva ${ }^{b}$ \\ a Instituto Federal Fluminense, R. Dr. Siqueira, 273, Parque Tamandaré, Campos dos Goitacazes, RJ, \\ Brazil \\ ${ }^{b}$ Laboratório de Materiais Avançados - LAMAV, Universidade Estadual do Norte Fluminense, Av. \\ Alberto Lamego, 2000, 28013-602, Campos dos Goytacazes, RJ, Brazil
}

Received: December 12, 2016; Accepted: February 12, 2017

\begin{abstract}
Spark plasma sintering is used to consolidate a WC-Co powder produced from milled discharged hard metal cutting inserts. The powder was mixed to $10 \%$ wt Co powder and spark plasma sintered (SPS) under $80 \mathrm{Mpa}$ pressure, at $1200^{\circ} \mathrm{C}$ with heating rate of $160^{\circ} \mathrm{C} / \mathrm{min}$. A reference alloy was prepared with a commercial WC powder and $10 \%$ wt. Co under the same conditions. The structures of both alloys were investigated by means of scanning electron microscopy and Vickers hardness. The results show structures with densities and hardness at the same level. SPS can be used to produce hard metal pieces directly from scrap powder without any prior chemical and thermal treatment.
\end{abstract}

Keywords: Hard metal, spark plasma sintering, hard metal scrap

\section{Introduction}

Hard metal scrap is the denomination of hard metal pieces like cutting inserts, drill bits etc, made of hard metal, after discharged. Until 2005, the hard metal manufacturers just collected the worn parts from their customers. After the elevation of costs of the raw materials, they started to process the scrap to recover part of the valuable elements in to reintroduce them in the production line. Presently, around $20 \%$ of all raw materials used in the manufacturing of hard metal pieces are estimated to come from scrap recycling ${ }^{1}$.

The hard metal scrap powder does not have controlled characteristics, such as composition. It results from milling of hard metal pieces of different products used in distinct applications that are collected. Not only Co, W, WC can be recovered, but also $\mathrm{Ta}, \mathrm{Nb}, \mathrm{Ni}$, Ti etc. The most used recycling route nowadays is the Zinc Recycling Process (ZRP).

In the ZRP the hard metal scrap in immersed in a liquid zinc bath. The zinc atoms diffuse into the hard metal binder to form a lower density alloy. The hard metal pieces bloat and crack. In the following, zinc is vacuum distilled. The bloated pieces now become sponge-like. The material now is milled to produce a powder with the same composition of the original scrap. The ZRP has low energetic cost, does not produce chemical by-products (zinc is reused), and does not need dedicated nor large facilities to be used. Its main disadvantage is that the scrap must be pre-selected to avoid the presence of unwanted elements in the final powder ${ }^{2,3}$.

SPS is a consolidation technique that uses simultaneous temperature and pressure to consolidate a powder. Heating is produced by the passage of an electric current through

* e-mail: angelus@uenf.br the sintering piece or the die. Heating rates from hundreds to thousands of grades per minutes are reached, depending on the equipment's power. In short times, high densities have been reported with the use of SPS in hard to sinter materials ${ }^{4-6}$. Although the presence of plasma has never been demonstrated, this denomination is still used to identify the technique ${ }^{7}$.

Hard metal is conventionally consolidated under low vacuum by liquid phased sintering, although for fine grained alloys most part of the densification occurs below the temperature of liquid formation. Nevertheless, liquid phase sintering is necessary to reduce porosity and promote homogeneity ${ }^{8}$. The higher temperatures to sinter in presence of liquid causes WC grain growth, depleting some mechanical properties. Another point that has to be observed in hard metal sintering is its carbon content, which can be influenced by the sintering atmosphere and the initial carbon gross content of the carbide powder. The alloy's carbon content must be inside a certain interval that depends on the binder content to avoid precipitation of unwanted phases that negatively influence the mechanical properties ${ }^{9}$.

The literature reports SPS of hard metal under different conditions of pressure, heating rate, final temperature, dwelling time, alloy composition and grain size ${ }^{10-13}$. Both solid and liquid state sintering were investigated. The reports point that high final densities and little or none grain coarsening obtained at lower temperatures and shorter times in comparison to other sintering techniques are characteristics of SPS.

\section{Materials and methods}

Two alloys were prepared and spark plasma sintered. The first alloy, named REF, was prepared with a commercial WC 
powder (mean particle size of $5.65 \mu \mathrm{m}$ ) and $10 \% \mathrm{wt}$. commercial Co powder (particle size below $53 \mu \mathrm{m}$ ). The second alloy, named REC, was prepared with a WC-Co powder produced by milling of hard metal scrap. The particle size is below 53 $\mu \mathrm{m} .10 \%$ wt. of the same Co powder as used in alloy REF was added to this WC-Co powder. The powders were mixed by hands to avoid any particle reduction and/or deformation.

The powder mixtures were placed inside a graphite die with cylindrical cavity with diameter of $15 \mathrm{~mm}$. A graphite foil is used to avoid the contact between the samples and the die parts.

The SPS machine presses the die punches with $80 \mathrm{MPa}$ pressure. A pulsating electric current passes through the die and the powders, heating the mixture at a rate of $160^{\circ} \mathrm{C} /$ mim, up to 1200 . The dwell time is 5 minutes. After that the electric current is switched off, the pressure is relieved and the sample cools in the furnace.

The sintered pieces are disc with diameter of $15 \mathrm{~mm}$ and thickness of around $3 \mathrm{~mm}$. After sintering the residues of the graphite foil are removed with a sandpaper and the density is measured by the Archimedes' technique. In the case of alloy REF, the theoretical density was determined by the rule of mixture. In the case alloy REC, the theoretical density could not be calculated because the density of the WC-Co powder from hard metal scrap is unknown. However, the theoretical density of this alloy is likely lower than that of alloy REF, since the cobalt content is the sum of $10 \% \mathrm{wt}$ commercial Co powder and the Co content of the powder recycled from scrap, which is unknown. Therefore, the REC alloy is richer in binder than REF alloy.

The samples were sectioned, embedded and polished for observation by SEM. The Vickers hardness was measured.

\section{Results and discussion}

Table 1 shows the measurements of density and hardness for both alloys, REC and REF.

The relative density of alloy REF attained $99 \%$. This is indication of high densification of the structure in spite of the short sintering time and the absence of liquid in the structure. Conventionally sintered hard metals (pressureless and liquid phased sintered) reaches relative density in order of $86 \%$, if sintered at $1275^{\circ} \mathrm{C}$ and the grain sized of the carbide phase is under $1 \mu \mathrm{m}$. At this temperature, liquid is about to be formed ${ }^{8}$. Therefore, the high density attained by SPS, under the mentioned conditions, show that the technique is indeed able to densify structures at low temperatures in short times, as reported in literature.

Both alloys have the same hardness level, if the dispersion is considered. At first, this could look unexpected, since alloy REC is richer in binder. Therefore, should be softer. Nevertheless, other factors influence hardness. For example, finer carbide powder, and the presence of harder phases, such as alumina and cubic carbides, as likely in unselected hard metal scrap, could improve hardness.
Table 1: Vickers Hardness and density of alloys REF and REC sintered at $1200^{\circ} \mathrm{C}$ for 5 minutes, and heating rate of $160^{\circ} \mathrm{C} / \mathrm{min}$. value in brackets is a relative density.

\begin{tabular}{lcc}
\hline Alloy & Vickers Hardness, GPa & Density, $\mathrm{g} / \mathrm{cm}^{3}(\%)$ \\
\hline REF & $13,68 \pm 2,01$ & $14,43(99,3)$ \\
REC & $14,30 \pm 0,64$ & 13,73 \\
\hline
\end{tabular}

Figures 1-4 exhibit SEM micrographs of the sintered structure of alloy REF.

The Co powder is much coarser than the WC powder. The technique used to mix the powders does not have enough energy to fragment hard agglomerates nor primary particles, or even to strain the Co particles. In Figure 1, homogeneously distributed darker spots are seen throughout the structure. They are Co particles. This shows that the mixture was able to disperse the phases without particle fragmentation.

The Co particles are elongated and aligned, as seen in Figure 2. (pointed by arrows). The elongation of the particles is caused by the compression under heating used in SPS. Then, elongation occurs in the direction orthogonal to the pressing direction. Some large pores are seen in places distant from the Co particles (in the rectangles drawn on the

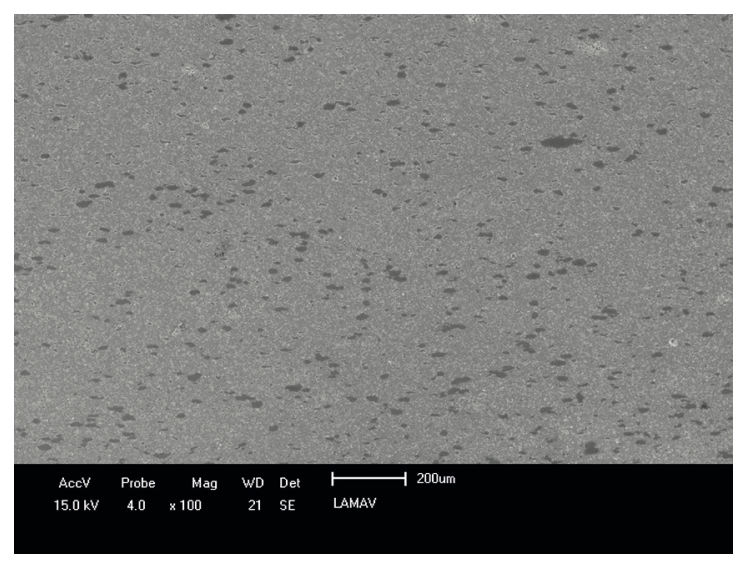

Figure 1. Structure of alloy REF. The distribution of Co particles throughout the structure is seen.

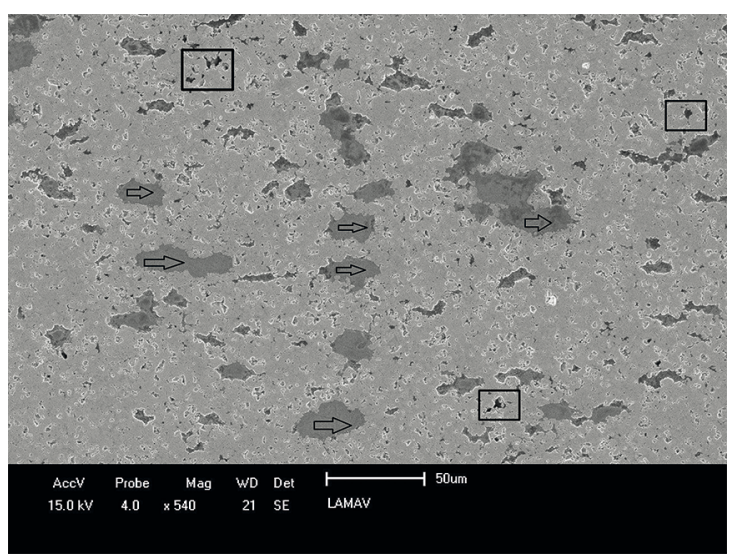

Figure 2. Structure of alloy REF. Elongated and aligned Co particles according to the pressing direction and pores (in squares) are seen. 


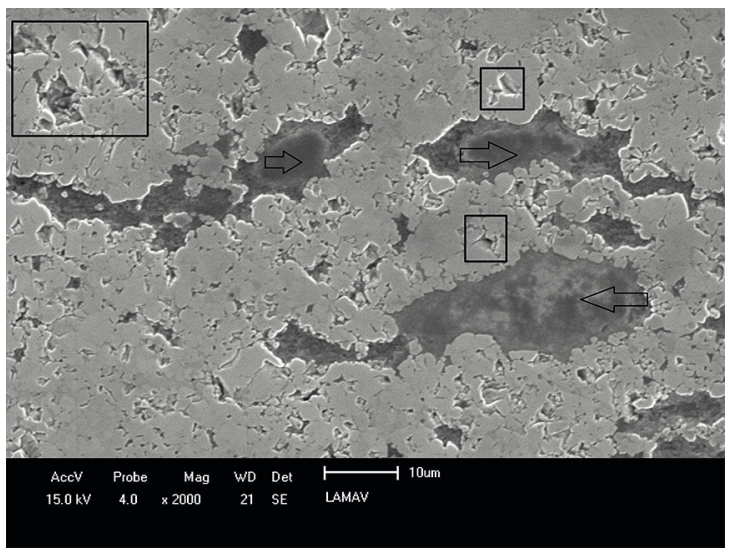

Figure 3. Structure of alloy REF. Pores (in squares) and elongated Co particles are shown.

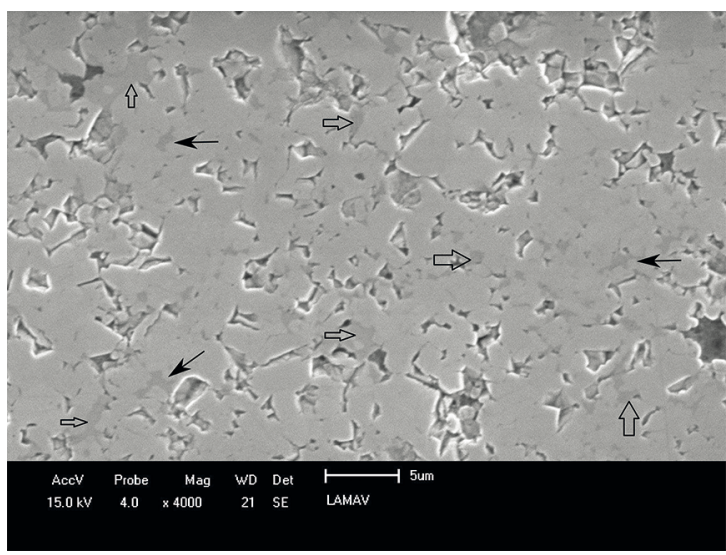

Figure 4. Structure of alloy REF. Region far from a Co particles. Boundaries of WC Grains with some Co binder and pores are seen.

image). Figure 3 shows in detail the elongated Co particles (arrows) and the pores (rectangles).

The images of the structure show that most of the Co phase is concentrated and not in contact with the WC particles as it happens in hard metals conventionally sintered, in which Co plays the role of binder of the WC particles, forming WC-Co agglomerates.

Figure 4 exhibits a magnified image of the contours of the WC particles. Darker regions can be seen in some contours, indicated by arrows. It is Co that reached these places through surface diffusion or dispersion of very small fragments of Co during the mixture. Therefore, although most of the Co phase is locally placed, there is a small volume that acts as a binder of the WC particles. Small but numerous pores are seen in the contours of the WC particles. These pores are left due to absence of binder in such regions.

The image of the structure confirms the high value of density measured for the sample. It is noticed that the outline of the WC particles resembles that of the original particles in shape and size. Therefore, no significant grain coarsening took place during sintering. This is another characteristic related to the SPS technique.
Figures 5-7 Exhibit SEM micrographs of the structure of alloy REC. In Figure 5, the elongated and aligned Co particles (darker gray shades) are seen as in alloy REF. The contours of large and brighter particles are also seen. They are the particles of the WC-Co powder, the hard metal scrap powder.

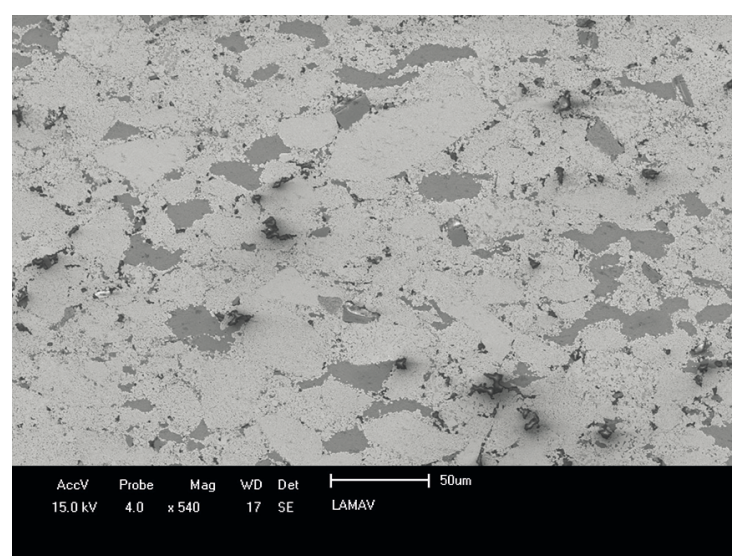

Figure 5. Structure of alloy REC. Elongated and aligned Co particles and particles of the WC-Co powder.

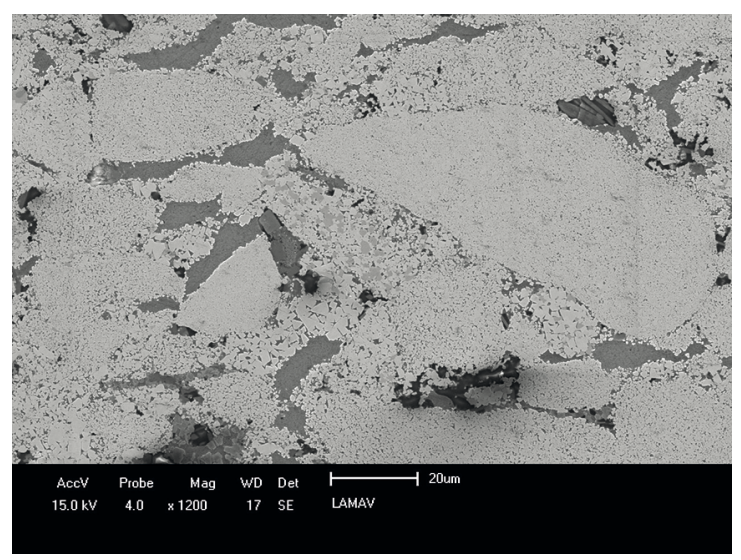

Figure 6. Structure of alloy REC. The matching of the contours of WC-Co and Co particles is shown.

Figure 6 shows how the WC-Co recycled particles are disposed in the structure. The particles of commercial Co and the hard metal scrap arrange themselves in such a way to eliminate the empty space that originally separates the particles. However, in some cases, the contours do not match perfectly and empty spaces (pores) are left.

The powder of hard metal scrap is produced by milling of hard metal pieces of different characteristics such as alloys of different composition and grain size distribution. This difference can be seen in Figure 7, in which WC-Co particles are shown. The regions marked with numbers 2,3 and 4 are particles of alloys made of WC powders of different grain sizes, fine, median and coarse, respectively. The particle marked with 1 is from an alloy with a cubic carbide, as the particles of darker gray shade beside the WC particles 


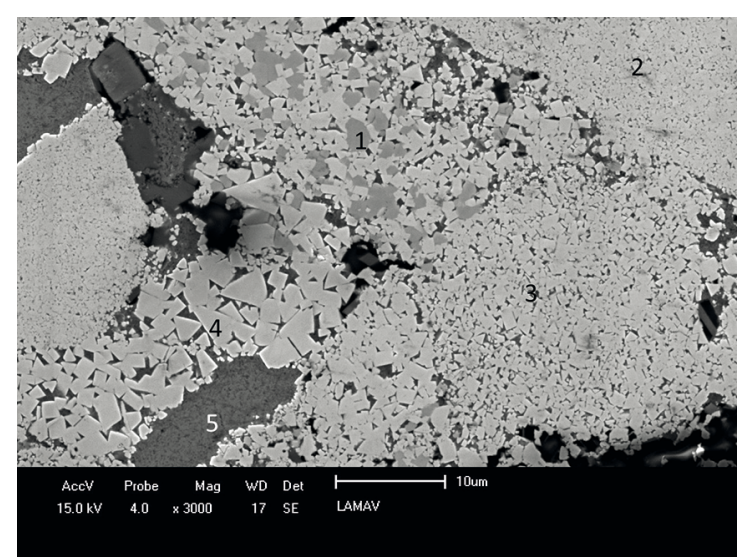

Figure 7. Structure of alloy REC. Particles of the WCOCo powder with different characteristics such as grain size and composition.

indicate. The region marked with 5 is likely a fragment of a cermet of a coating of hard metal piece.

The contours of the particles are clear. In some places, the match of the contours of different particles is not perfect and pores are left, but in most cases, the match is perfect. The presence of few and small pores confirm the high density measured for this alloy.

Alloy REC is as hard as alloy REF in spite of its higher Co content. The reason could be the presence of harder phases, such as hard coatings, cubic carbides and particles with fine WC grain size.

\section{Conclusions}

Sintering of a WC-Co powder obtained by milling of hard metal scrap by spark plasma is able to densify structures near full density with hardness comparable to another made of commercial WC and Co powders. SPS of recycled powders of hard metal scrap can be used to produce hard metal pieces without the mixture with commercial WC powder. The structures can be produced by solid state sintering in short times without grain coarsening.

\section{Acknowledgements}

The authors acknowledge CAPES and FAPERJ for the financial support.

\section{References}

1. Netto AB. Reciclar É Preciso. Usinagem Tech. 2010;1:6-11.
2. Freemantle CS, Sacks N, Topic M, Pineda-Vargas CA. Impurity characterization of zinc-recycled WC-6wt.\% Co cemented carbides. International Journal of Refractory Metals and Hard Materials. 2014;44:94-102.

3. Lassner E, Schubert WD. Tungsten: Properties, Chemistry, Technology of the Element, Alloys, and Chemical Compounds. New York: Springer Science; 1999.

4. Tokita M. Mechanism of spark plasma sintering. In: Proceedings of the International Symposium on Microwave, Plasma and Thermomechanical Processing of Advanced Materials; 1997; Osaka, Japan. p. 69-76.

5. Munir ZA, Anselmi-Tamburini U, Ohyanagi M. The effect of electric current and pressure on the synthesis and consolidation of materials: A review of the spark plasma sintering method. Journal of Materials Science. 2006;41(3):763-777.

6. Dupuy AD. Modeling and Experimental Studies of Densification Rates in Current Activated Densification. [Masters Thesis]. Riverside: University of California; 2011.

7. Hulbert DM, Anders A, Anderson J, Lavernia EJ, Mukherjee AK. A discussion of the presence of plasma in spark plasma sintering. Scripta Materialia. 2009;60(10):835-838.

8. Da Silva AGP. Study on sintering and grain growth of WC-based hard metals. [Doctoral Thesis]. Vienna: Institut für Chemisch Technologie Anorganischer Stoffe, Technische Universitaet Wien; 1996.

9. Schubert WD, Fugger M, Wittmann B, Useldinger R. Aspects of sintering of cemented carbides with Fe-based binders. International Journal of Refractory Metals and Hard Materials. 2015;49:110-123.

10. Huang SG, Li L, Vanmensensel K, Van Der Biest O, Vleugels J. $\mathrm{VC}, \mathrm{Cr}_{3} \mathrm{C}_{2}$ and $\mathrm{NbC}$ doped WC-Co cemented carbides prepared by pulsed electric current sintering. International Journal of Refractory Metals and Hard Materials. 2007;25(56):417-222.

11. Kim HC, Oh DY, Shon IJ. Sintering of nanophase WC$15 \mathrm{vol} \%$ Co hard metals by rapid sintering process. International Journal of Refractory Metals and Hard Materials. 2004;22(4-5):197-203.

12. Sivaprahasam D, Chandrasekar SB, Sundaresan R. Microstructure and mechanical properties of nanocrystalline WC-12Co consolidated by spark plasma sintering. International Journal of Refractory Metals and Hard Materials. 2007;25(2):144-152.

13. Bonache V, Salvador MD, Fernández A, Borrell A. Fabrication of full density near-nanostructured cemented carbides by combination of $\mathrm{VC} / \mathrm{Cr}_{3} \mathrm{C}_{2}$ addition and consolidation by SPS and HIP technologies. International Journal of Refractory Metals and Hard Materials. 2011;29(2):202-208. 